\title{
Setting Up an Integrated Social Security System
}

\section{Athar Hussain}

\section{OpenEdition}

\section{Journals}

Édition électronique

URL : http://journals.openedition.org/chinaperspectives/2083

DOI : 10.4000/chinaperspectives.2083

ISSN : 1996-4617

\section{Éditeur}

Centre d'étude français sur la Chine contemporaine

\section{Édition imprimée}

Date de publication : 15 septembre 2007

ISSN : 2070-3449

\section{Référence électronique}

Athar Hussain, «Setting Up an Integrated Social Security System », China Perspectives [En ligne], 2007/3 | 2007, mis en ligne le 01 septembre 2010, consulté le 28 octobre 2019. URL : http:// journals.openedition.org/chinaperspectives/2083; DOI : 10.4000/chinaperspectives.2083

(C) All rights reserved 


\title{
Setting Up an Integrated
}

\section{Social Security System}

\author{
ATHAR HUSSAIN
}

As part of its plan to establish a harmonious society, the Chinese Communist Party has resolved to establish by 2020 a social security system covering both urban and rural populations. A common assumption is that the integrated system would provide to the whole population the same high level of protection that a section of the urban population currently enjoys.

This article will provide an overview of the current situation and consider the prospects for the establishment of such a system by 2020 . The aim is ambitious and the time available for achieving the target is very limited. However, two of the principal pre-conditions for achieving the target are present. First, there has been a dramatic improvement in public finances and the trend looks likely to continue. The implication is that the government would be increasingly capable of covering the extra cost of setting up an integrated social security system. Second, the leadership is strongly committed to establishing such a system. Yet a seamless and fully operational system is highly unlikely.

$\mathrm{C}$ hina's current social security system is largely a development from the second half of the 1990s, one that is still under construction, and not yet complete. Pre1978, income maintenance (ensuring basic subsistence to the population) was, as in other command economies, woven into the fabric of economic organisation. The able-bodied were expected to work and, if they were urban residents, the government allocated them jobs, albeit very low paid. A delayed consequence of these guaranteed jobs was the serious problem of a surplus labour force in the state and urban collective sector, which became a major concern for the government in the 1990s. If they were rural residents, the collective unit of which they were a part, usually a production team, assigned them tasks entitling them to a share in the collective income. This regime of "welfare through work" was complemented by a policy of keeping the prices of necessities low and the provision of relief to the rural localities struck by natural disasters or classified as endemically poor. The payment of an allowance in cash and kind, as in means-tested social assistance, was confined to a very small group characterised by the "Three Nos": not able to work, no savings and no relatives to depend on. Government and state enterprise employees enjoyed a range of benefits, including "labour insurance". The rural and urban populations were then also largely separate, very much unlike today where, because of rural-to-urban migration and the re-designation of rural counties as urban districts due to urbanisation, the rural and urban populations have become much more integrated.
Notably absent from the social security arrangements were two schemes that are common in welfare states and would later be introduced into the Chinese social security system. Of these two schemes an unemployment insurance scheme was introduced in 1986 as the complement to the fixed-term employment contracts in the state sector and generalised to the whole of the urban labour force in 1998. The other scheme was means-tested social assistance for all, including those able and willing to work but without a job. Such a scheme, termed "Minimum Living Standard Assistance" (MLSA), is a recent innovation. The MLSA scheme, covering the urban population, was introduced in 1998 and for the rural population in 2007. The generalisation of MLSA to the whole urban population and the extension of Unemployment Insurance (UI) to the urban labour force marked the culmination of the growing recognition on the part of the government that it could no longer guarantee jobs to the urban labour force as it was able to do in the past.

The labour insurance system, which covered state sector employees and larger collective enterprises and was the precursor of the present-day "social insurance", was originally set up in the 1950s with an administrative structure of its own and financed by employer and employee contributions. It was transformed into work-unit or occupational welfare during the period of the Cultural Revolution. Over this period, retirement was suspended; employees worked for as long as they were physically able. Thus the reform period started with a social security system that was partly out of operation 
and comprised a disparate collection of arrangements to cater for various contingencies.

\section{The Current Social security complex - An Overview}

The current assortment of social security schemes do not constitute an integrated whole, hence the term "complex" is used instead of "system". Broadly they are aimed at the following:

- Poverty alleviation

- Income maintenance in the event of unemployment, occupational injury, sickness and retirement

- Subsidised, including free, medical care as and when needed.

This list raises the question of the effectiveness of these aims at the macro level. A quantitative answer is not possible but one can convey an idea of their scale by pointing to the limits and scope of the impact of social security schemes. Concerning poverty alleviation, the reform period (since 1979), has witnessed a dramatic reduction in poverty in rural areas. Following the distribution of land to rural households, which started the reform process, the number of rural poor fell from 250 million in 1978 (30.7\% of the rural population) to 85 million in 1990. Much of this fall was due to output growth, while anti-poverty schemes played a negligible role or none at all. Arguably the three schemes, the "basic living allowance for laid-off employees," UI, and the MLSA played a crucial role in preventing urban poverty. They constituted an overlapping three-line defence against the urban population slipping into poverty and became fully operational in 1997-99 as the state sector was shedding labour on a massive scale.

Turning to income maintenance under various contingencies, such as unemployment and retirement, its effectiveness is limited by the fact that less than half of the urban labour force participates in the social insurance schemes that cater to these contingencies. As for the subsidisation of medical care by the rural and urban medical insurance schemes, this has a "very limited" impact on the cost of the medical care to patients. Faced with declining tax revenue to GDP ratio over the first twenty or so years of the reform period, the government sharply reduced direct subsidies to medical care. ${ }^{(1)}$ Added to this, the insurance schemes cover a small percentage of medical care costs. As a result, by international standards the Chinese population bears a high percentage of the cost of medical care and a substantial slice of the population thus forgoes necessary medical treatment, a figure as high as 50\% according to a Ministry of Health survey (see article of Sarah Cook in this special feature).

The schemes that make up the social security complex, can be divided into the familiar categories of "social insurance" and "social assistance (social safety net)". (2) Both categories include a variety of schemes and the distinction between them is based on two salient aspects: the conditions attached to the provision of benefit (entitlement qualification); and the method of financing.

As is usual, social assistance is conditional on means testing. However, social assistance that is free of additional conditions, such as being unable to work and without close relatives is a recent development. The means test in China can be stringent and intrusive and may discourage a substantial number of genuine cases from claiming assistance. Being non-contributory the social assistance schemes have to be financed from general government revenue, which, in the Chinese context, leads onto the vexed issue of the apportionment of expenditure responsibilities among various government tiers. The issue has risen in importance in recent years with the establishment of a number of new social assistance schemes and a huge growth in the number of their beneficiaries. Prominent examples include two schemes: the MLSA, which was generalised in 1998, and for which the number of beneficiaries has since risen from 1.8 million to 22.3 million in $2005 ;^{(3)}$ and the new Rural Co-operative Medical Insurance Schemes (RCMIS), which began to be set up in 2003, are heavily subsidised. On $30^{\text {th }}$ June 2007, participants in RCMIS totalled 720 million, around $85 \%$ of the rural population. ${ }^{(4)}$ The dramatic increase in the number of beneficiaries of these two schemes is due largely to the central government covering most of the cost of the schemes and thus circumventing the issue of the division of costs among government tiers.

The contributory schemes fall into two categories: social insurance and the two rural schemes including local pension schemes which cover a rural population of 54 million (only $7 \%$ of the total) and provide no more than part-subsistence. Although there is individual contribution in RCMIS, the scheme is better regarded as a social assistance scheme because the government (central and territorial) pays $80 \%$ of

1. Hussain, A and Stern, N, Public Finances in Transition, Mimeo, 2007.

2. For an account see the "White Paper on Social Security," Ministry of Labour and Social Security, September 2004

3. Ministry of Civil Affairs, 2006, China Civil Affairs Yearbook 2005, Beijing, China Statistics Press.

4. China View, Xinhua Net, 5 September 2007. 

localities; it is high in Shanghai and other coastal provinces and low in the interior provinces. In law, participation in social insurance is mandatory for the whole urban labour force. In practice, the participation rate is high in the state sector and in large non-state units; and the rate is low in small units, mostly in the service sector. As outlined earlier, a particular impediment to the extension of social insurance is the steady shift of employment away from the state sector into small enterprises in the services.

Social insurance provides limited social security cover in that it not only excludes, by design, non-participants in the labour market, but also fails by a wide margin to cover the whole urban labour force. The implication is that a social security system has to include both social insurance and social assistance schemes, if it is to cover a substantial section of the population, which is what the Chinese and other social security systems do. The transition towards a market economy has drastically curtailed the scope of "welfare through work" and the void that created has been largely filled by social assistance schemes. The trend looks likely to continue.

\section{Two Salient Features}

Taken together, the contributory and non-contributory schemes are characterised by two salient features, ramifications of which run wide and deep throughout the system:

- Segmentation and striking differences in provision across groups

- Highly decentralised financing and management.

\section{segmentation}

The abiding feature of the Chinese social security complex has been the deep division between the rural and the urban populations and the glaring contrast between their respective social security entitlements. This division dates from the pre-reform period (pre-1978) and still survives, though increasingly blurred at the edges. All social security schemes are targeted at either the urban or rural population; as yet not one covers both. The urban population benefits from a complementary combination of contributory social insurance, providing old-age pension, work injury compensation, healthcare insurance, maternity benefit and unemployment compensation, and means-tested social assistance (MLSA), which bridges any shortfall of household per capita income from the local poverty line.

In a stark contrast to the comparatively high level of social security enjoyed by the urban population, the social security provision for the rural population is sparse. The rural schemes constitute a disparate combination: they date from various periods and were established on a piecemeal basis. Bar a few minor exceptions, they are non-contributory social assistance schemes, aimed at alleviating severe hardship and narrowly targeted, either on households passing a means test or the residents of designated localities. The methods of financing vary across schemes and the responsibility for their supervision and operation is split between different organisations. Some are financed and managed entirely by the local government and villages. ${ }^{(7)}$ Others are jointly financed by several government tiers. They do not form a coherent system-hence the term "complex" rather than "system".

As pointed out above, the contributory (social insurance) schemes for the rural population are few. The imbalance between the two types of scheme is due in part to the common difficulty in collecting contributions in a rural economy where income is only partly monetised. It is due also to the separation of rural and urban schemes. Thus the sections of the rural population are excluded from urban schemes even when there is no real impediment to their participation. Of the rural labour force of 485 million, 143 million (28\%) are employed full time in town and village enterprises (TVEs). ${ }^{(8)}$ Although a substantial percentage of them are wage employees in sizeable enterprises, they are excluded from social insurance simply on the basis of their designation as "rural." The paucity of rural contributory schemes matters because they can serve objectives that are beyond the scope of social assistance schemes, for example by providing a pension in old age or medical insurance without means testing. An urban bias in social security provision is not particular to China, being commonly seen in developing economies. The bias is to a degree unavoidable, given serious problems in designing contributory social security (social insurance) schemes for the self- or the informally employed. It occurs even in developed economies. There are two professed rationales for the limited social protection cover in China's rural areas. One is that each rural household is assigned a plot of agricultural land that serves as a floor to household income, a feature that is particular to China and a few other economies. The other is the high cost of introducing a social security regime comparable to the one in urban areas, relative to the limited capacity to collect taxes and social security contributions in rural areas. Both are valid justifications,

7. The category "village" refers to both governmental and non-governmental units. It is qualified as "administrative" when it refers to the former.

8. NBS (State Statistical Bureau), 2006b, China Labour Statistical Yearbook 2006, Beijing 
but only under strong qualifications. The protection provided by land plots is highly variable and has diminished over time because of the combination of the increase in the rural population and the diversion of land to non-farm uses. The latter has given rise to a substantial rural population without any land. As for the second, the rural-urban distinction is maintained even where it is possible to extend some schemes to the rural population. For example, 143 million employees of TVEs are excluded from social insurance, even when employed in large enterprises on terms similar to those in urban enterprises. The differing treatment of the urban and rural populations is also based on the anachronistic assumption that the rural labour force is self-employed and engaged in farming. For the purposes of social security, the terms "rural" and "urban" are defined with reference to the entry in the hukou (ID register), not the actual place of residence. As a result persons living and working in cities on a long-term basis may still be classified as "rural" and excluded from the schemes for the urban population. From the point of view of social security, the population is divided along two lines: first, rural and urban, and second, permanent residents and immigrants, a distinction which is mainly relevant in an urban setting. In the past, there also existed a deep division between the state sector employees and other employees, which has almost disappeared. The first two divisions are fading, but will still take some time to disappear completely. The ubiquitous hukou, "ID registration", which was first introduced in the 1950s still survives, though modified. It records personal details and resembles the national identity card schemes in many European countries, except in one crucial respect. That is, the permanent place of residence in the ID register can only be altered by administrative discretion and does not change with migration. Thus hukou partakes of a central feature of citizenship and is similarly used to control migration or to sort individuals into categories with differing entitlements. Following a lowering of impediments to travel and labour mobility and the displacement of rationing with an open market in necessities, migration grew and became substantial in the 1990s. As a result, the hukou has mutated into a mechanism for dividing the population into "permanent residents" and "outsiders" (migrants) with differing access to social goods, such as basic education, and opportunities in the labour market. The migrant population ${ }^{(9)}$ is huge-just over 134 million according to the 2000 population census, around $11 \%$ of the then national population. ${ }^{(10)}$ In the Chinese context, the category "migrants" is an anomaly created by treating individuals as residents of a locality other than where they have actually been living and working for a long time. With a large percentage excluded from participation in social insurance and means-tested social assistance, the migrant population represents a huge blind spot in the social security cover.

\section{Decentralisation}

Both rural and urban social security systems are highly decentralised, the former more than the latter. In the case of the urban schemes, although social insurance and MLSA are based on regulations issued by the central government, many of the details of the schemes are left to the discretion of the provincial or municipal governments. More consequential, for both social insurance and MLSA the budgetary units are 269 cities (excluding county-level cities and towns); (II) and generally cities are expected to cover from their own budgets any deficit on social insurance and the cost of MLSA in their respective jurisdictions. In some cities, such as Chengdu, the budgetary unit is not the city itself but its constituent units, districts. As is to be expected, the balance between contributions and expenditure varies across cities, depending on, for example, the number of pensioners relative to contributors and the unemployment rate, and so do their general finances. As a result, the operation and benefit levels can vary widely across cities even within the same province. Apart from a few very large ones, cities are too small a budgetary unit to provide sufficient risk pooling to ensure the sustainability of social insurance. The financial decentralisation also has an adverse effect on the operation of MLSA, which has to be financed from the general revenue of the cities. In many cases, cities with a comparatively heavier burden of MLSA have more strained budgets because the factors that cause households to slip into poverty also act as a drag on city finances.

Decentralisation in rural areas runs deeper than in urban areas. Apart from a few schemes run by the centre or by provincial governments, most of the rural social security schemes are organised at the grass roots level of villages. Such schemes include assistance to poor households and the rural pensions and co-operative medical insurance schemes. The initiation, operation and financing of rural schemes

9. In Chinese statistics a migrant is defined as a person living for six months or more in a locality different from the registered place of residence.

10. NBS (State Statistical Bureau), 2002, The Population Yearbook of China, Beijing, China Statistical Press.

11. Chinese cities divide into a five-level hierarchy: provincial, sub-provincial, prefectureand county-level. All included there are 662 cities and towns. The above figure of 269 excludes 393 county-level cities. 
largely rest with lower tier governments; the higher government tiers (provinces and the centre) in most cases confine themselves to the supervision and setting-up of pilot schemes. Associated with this, variations in social security provision are much wider in rural than in urban areas.

There are ad hoc transfers from the central and provincial governments to lower tier governments so they can meet their social security obligations under social insurance and MLSA. But there is as yet no regular framework for fiscal transfers from higher to lower government tiers to cover expenditure responsibilities of the latter. An overhaul of the system of inter-governmental finances has been high on the reform agenda for a number of years but it still remains to be realised. A pooling of social insurance contributions and expenditures at the provincial level is the policy aim. There are 11 or so provinces, including province-level cities, that in various ways pool contributions and expenditure. But there is as yet no preferred framework for pooling. The upgrading of the level of budgeting from cities to provinces for social insurance can take a number of forms ranging from full integration to compensatory transfers within a decentralised system. Each of these has implications for the administrative structure. The national pooling of social security contributions and expenditures does not seem to be immediately feasible. It would also be inequitable in that, under the present financing arrangements, poorer provinces would be making transfers to richer provinces because the latter tend to have a higher ratio of pensioners to contributors than do the former.

\section{Integrated Social security system}

In October 2006 the Central Committee of the Chinese Communist Party, as a part of the plan to establish a harmonious society, resolved to establish by 2020 a social security system covering both urban and rural populations. Though not spelt out explicitly, the common assumption is that the integrated system would provide to the whole population the same high level of protection that a section of the urban population currently enjoys. The promised system will not only close the rural-urban gap but also fill the large gaps in coverage that mar the present rural and urban systems. The goal is ambitious and the time allowed to achieve the goal is very limited. The closing of the rural-urban gap will require a lot more than simply raising the social security provision in rural areas to the level in urban areas. The rural-urban distinction is not confined to the social security field but runs wide and deep to the institutional structure of the government, public finances and the provision of social goods such as basic education and healthcare.

The establishment of an integrated system has to take into account the implications of the following:

- The rural per capita income is a small fraction of the urban per capita income. In 2005, the rural net income per capita was slightly less than one-third of the urban disposable per capita income.

- The variation in rural per capita income is far wider than that in urban per capita income.

- A large percentage of rural households have a piece of land each, which historically has served as a justification for providing restricted social security cover to the rural population.

- Internal migrants are huge in numbers and mobile across localities.

The first suggests that applying the same schedule of contributions and benefits for social insurance schemes to both rural and urban populations may lead to a much lower participation rate among the former. There are two possibilities for raising the participation rate among the rural population to that of the urban population. One is to charge rural residents a lower contribution rate in return for lower benefits. This is the approach used by Shanghai in extending social insurance to its rural population. It is a temporary solution to the problem posed by the rural-urban income gap and cannot be a permanent feature of the integrated scheme. The other approach is to keep the same schedule of contribution and benefit but raise the government contribution to offset any financial shortfall caused by the inclusion of the rural population. This fits in with the spirit of an integrated social security system. But it is premised on the continued improvement in public finances as seen over the last few years.

The greater variation in income per head in rural localities than in comparable urban localities suggests a fundamental incompatibility between an integrated social security system and the financial and operational decentralisation that characterises the present system. The obverse of decentralisation is variation in the levels of provision and facilities. Extending the current system to cover rural localities would further widen the variation and may make the integrated system non-viable. The implication is that the construction of an integrated social security system has to go together with raising the budgetary unit to the provincial level.

Turning to the land plot as a substitute for social security, the average area of land plot per household varies across villages (even in close vicinity) but also according to climate and lo- 
$\int$

$\geq \quad$ cation. The cultivated area per rural inhabitant is low: slightly less than one-fifth of a hectare (0.19) ${ }^{(12)}$ and falling, due to the diverting of land for non-agricultural uses. The implication is that although land plots have reduced the incidence of rural poverty, they do not provide full protection against fall into poverty. Further, not all rural households have a land plot and the number of landless households has in recent years risen sharply. A rough estimate puts their number at forty million which is around $10 \%$ of all rural households. The argument is that treating household land plots as a justification for providing the rural population with a reduced social security cover was weak to begin with and has been rendered even weaker by recent developments. There is a strong argument for completely de-linking land tenure from the development of social security for the rural population.

Migrants represent a huge blind spot in the current social security coverage. This is due to two factors. First, because of the way the hukou system currently operates, migrants continue to not be treated as residents of a locality where they have actually been living and working for a long time. Second, current social security schemes are financed and operated on a highly decentralised basis and there is as yet no national framework for the portability of contributions and benefits.

A vast majority of migrant workers are from rural localities and their inclusion in the social security system would seem to be a first step towards the construction of an integrated system. There are two aspects to the participation of immigrants in social insurance schemes: collection of contributions and disbursement of benefits.

The problems raised by the first are, in principle, the same for migrants and residents. The only difference is that migrants are more likely to be in jobs, such as casual or informal employment, with low rates of social insurance cover. Concerning the second, one needs to distinguish between schemes where contributions and benefits run concurrently and where they are separated in time. The former include disability and injury compensation and medical care insurance, which can be extended to migrant workers without any problem. Some cities already do this. The latter group include old-age pensions, which raises a particular problem because of the long time gap between the payment of contributions and the receipt of benefits, and the absence of a national framework for the accumulation of contributions paid in various localities and the portability of pensions. An interim solution to the problem is to set up a special scheme for migrant workers that is managed by the central government.
So what are the prospects for the establishment of an integrated social security system by 2020 ? We can at least emphasize that two of the principal pre-conditions for the development of such a system are now present. First, the last few years have seen a dramatic improvement in public finances and the trend looks likely to continue. Thus, the implication is that the government would become increasingly capable of covering the extra cost of setting up an integrated social security system. Second, the leadership is strongly committed to establishing such a system. $\bullet$
12. The actual figure depends on the definition of the land area (numerator) and of the denominator. Here, the land area is taken to be the sown area in 2000 and the total rura population as the denominator. The area of land per person will be higher if the labour force employed in farming were considered instead of the rural population. 